\title{
LA CUESTIÓN \\ DE CONSTITUCIONALIDAD
}

\author{
LUZ, BLLNES AI.DUNATE \\ Profesora Titular de Derecho Constitucional \\ Facultad de Derecho-Lniversidad de Chile
}

\section{EL ART. 82 DE IA CONSTITUGIÓN DE 1980 ESTABLECE EN FORMA TAXATIVA LAS ATRIBUCIONES DEI. TRIBUNAI. CONSTITUCIONAI}

Del análisis de esta norma resulta que el constituyente ha establecido un control de constitucionalidad de los proyectos de ley, sin que pueda este órgano jurisdiccional revisar la constitucionalidad de las leyes ya promulgadas y publicadas, es decir, de las normas vigentes.

En el artículo mencionado se consagran dos tipos de control, distinguiéndose para este efecto los proyectos de leyes orgánicas constitucionales e interpretativas de los proyectos de leyes ordinarios.

Respecto de los primeros el constituyente señala:

"Son atribuciones del Tribunal Constitucional: 1" Ejercer el control de constitucionalidad de las leyes orgánicas constitucionales antes de su promulgación y de las leyes que interpreten algún precepto de la Constitución".

Además, el art. 82 establece que "en el caso del número 1, la Cámara de origen enviará al Tribunal el proyecto respectivo dentro de los cinco días siguientes a aquel en que quede totalmente tramitado".

De lo anterior se desprende con claridad que tratándose de este tipo de leyes el Tribunal ejerce un control preven tivo y obligatorio.

Distinto es el caso de las leyes ordinarias respecto de los cuales el art. 82 No 2 de la Constitución dice:
"Son atribuciones del Tribunal Constitucional: resolver las cuestiones sobre constitucionalidad que se susciten durante la tramitación de los proyectos de ley o de reforma constitucional y de los tratados sometidos a la aprobación del Congreso". 
La misma disposición agrega más adelante:

"En el caso del número 2, el Tribunal sólo podrá conocer de la materia a requerimiento del Presidente de la República, de cualquiera de las Cámaras o de una cuarta parte en ejercicio siempre que sea formulado antes de la promulgación de la ley".

Este tipo de control tiene sustanciales diferencias con el anterior, pues si bien reviste el carácter de preventivo es, esencialmente, facultativo y para que pueda operar es menester que se reúnan los siguientes requisitos:

a) Que exista una cuestión de constitucionalidad;

b) Que se suscite durante la tramitación de un proyecto de ley de una reforma constitucional o de un tratado sometido a la aprobación del Congreso;

c) Que el requerimiento lo promueva el Presidente de la República, las Cámaras o una cuarta parte de sus miembros en ejercicio, y

d) Que se formule antes de la promulgación de la ley.

\section{LOS ORÍGENES DE ESTE SEGUNDO TIPO DE CONTROL LLAMADO, TAMBIÉN, EL RECURSO PREVIO, LOS ENCONTRAMOS EN EL DERECHO COMPARADO, ESPECIALMENTE, EN LAS ATRIBUCIONES DEL CONSEJO CONSTITUCIONAL FRANCÉS}

En Francia al igual que en la Constitución de 1980 las leyes orgánicas constitucionales están sometidas al control obligatorio del Consejo Constitucional (art. 46 de la Constitución Francesa) y debe requerir este control el Primer Ministro.

Respecto de las leyes ordinarias hay que distinguir la situación anterior a la reforma de 1974 y la posterior a ella.

En el texto primitivo de la Constitución Francesa las autoridades con atribuciones de impugnación eran: el Presidente de la República, el Primer Ministro, el Presidente de la Asamblea y el Presidente del Senado.

Sobre el particular Favoreu nos dice: "De hecho, estas autoridades han sometido poquísimos casos ante el Consejo Constitucional, y el desarrollo del control de constitucionalidad de las leyes habría sido muy débil 
si se hubiera mantenido este sistema" (Los Tribunales Constitucionales, pág. 107).

establece:

En 1974 se reforma la Constitución y en el artículo 61 inc. 2 se

"Con los mismos fines las leyes pueden ser enviadas al Consejo Constitucional antes de su promulgación por el Presidente de la República, el Primer Ministro, el Presidente de la Asamblea Nacional, el Presidente del Senado o 60 diputados o 60 senadores.

Esta atribución tiene gran importancia porque la oposición dispone de un medio para asegurarse de que la mayoría no traspase los límites fijados por la Constitución.

La doctrina ha denominado a esta facultad del Tribunal Constitucional de conocer proyectos que están aún en tramitación "el recurso previo" y es inevitable que produzca una tensión entre el órgano legislativo y el que ejerce el control de constitucionalidad.

Patricio Zapata en su obra "La jurispruencia del Tribunal Constitucional", págs. 166 y 167 indica ciertas críticas que se han formulado al control previo como también señala argumentos que serían favorables:

"Los críticos sostienen que el recurso previo puede transformarse en una herramienta de las minorías para obstaculizar y frenar el trabajo legislativo. Más aún, la sola amenaza de presentar el recurso puede transformarse en un instrumento de presión sobre la mayoría".

Entre los argumentos favorables el autor cita los siguientes:

"La necesidad de disponer de una instancia dotada de legitimidad suficiente y poder para resolver los conflictos de interpretación que se produzcan entre los órganos colegisladores. La falta de tal arbitraje, se indica, tiene un efecto perturbador y paralizante sobre el sistema político".

"Así argumentó, por ejemplo, el presidente Frei Montalva en 1970 al justificar la reforma constitucional que creaba el primer Tribunal Constitucional chileno".

Como segundo argumento dado por el comentarista en favor del recurso previo: "consiste en destacar lo ventajoso que resulta poder disponer tempranamente de una opinión definitiva sobre una cuestión de constitucionalidad, y no tener así que esperar hasta la conclusión del trámite legislativo para obtener recién entonces una resolución que puede llegar a anular el trabajo legislativo de meses o años".

Si bien el origen en el derecho comparado de nuestro recurso previo lo encontramos básicamente en las atribuciones del Consejo Constitucional Francés, en España aparece este instrumento jurídico en 1984 creado 
por la Ley Orgánica Constitucional respectia fundándose en el art. 161 de la Constitución Española que dice:

"El Tribunal Constitucional Español es competente para conocer de las demás materias que le atribuya la Constitución o las leyes orgánicas".

Con relación a esta atribución García Enterría mencionado por Patricio Zapata en la obra citada sostiene: "la técnica del recurso previo podría justificarse sólo si ésta pudiese solventarse en plazos mínimos comoes el modelo francés, modelo de la técnica del control previo: un mes e incluso 8 días si el Gobierno declara la urgencia. Como ése no es nuestro caso su admisión equivale a un veto suspensivo de la minoría por largos períodos de tiempo, lo cual resulta de imposible justificación.

Esta crítica no cabe hacerla en Chile pues de acuerdo con el art. 82 en el caso del número 2 "el Tribunal deberá resolver dentro del plazo de diez días contados desde que reciba el requerimiento, a menos que decida prorrogarlo por otros diez días por motivos graves y calificados”.

\section{LA CONSAGRACIÓN DEL RECLRSO PREVIO EX EL ART. 82 DE LA CONSTITLCIÓN DE 1980 TIENE SLS ANTECEDENTES NO SÓLO EN EL DERECHO COMPARADO SINO TAMBIÉY EX DIVERSOS PROBLEMAS DE CARÁCTER CONSTITLCIONAL. ACAECIDOS DLRANTE LA VIGENCIA DE LA CONSTITLCIÓN DE 1925}

En Chile bajo la Constitución de 1833 tanto los tribunales como la doctrina estuvieron contestes en que la Corte Suprema carecía de atribuciones para ejercer un control de constitucionalidad de las leves, no pudiendo declarar su inconstitucionalidad.

Se basaban principalmente en que no existía disposición expresa que los autorizara para ejercer estas atribuciones y además, en el art. 164 de dicho cuerpo legal que autorizaba, expresamente, al Congreso para resolver los posibles problemas de interpretación que presentaren las leves.

"Sólo el Congreso, conforme a lo dispuesto en los artículos 40 y siguientes podrá resolver las dudas que ocurran sobre la inteligencia de alguno de sus artículos".

Es así como uno de los redactores de la Constitución de 1925 y destacado constitucionalista José Guillermo Guenra decía, refiriéndose a la situación reinante bajo la vigencia de la Constitución de 1833, que el Poder Legislativo estaba revestido de una omnipotencia casi divina que le permitía 
dictar leyes inconstitucionales a sabiendas que adolecían de defectos, pero seguro que nada ni nadie podría estorbar su cumplimiento, en forma autorizada y eficaz.

Durante la elaboración de la Constitución de 1925, se pretendió por parte de los comisionados y especialmente por parte del presidente Arturo Alessandri, poner fin a la pasividad judicial y con tal objeto se entregó a la Corte Suprema de justicia la facultad de velar por la supremacía constitucional de manera que este órgano determinara si las leyes que en el futuro se dictaran atentaban o no contra la Constitución.

La jurisprudencia de la Corte Suprema durante la vigencia de la Carta de 1925 fue unánime en no aceptar el control de forma de las leyes, de manera que el control, que se ejerció bajo la vigencia de este texto fue judicial a posteriori y de efectos particulares o concretos.

Debido a lo limitado del control que ejercía la Corte Suprema el ambiente jurídico y principalmente universitario, se mostró desde fines de la década del 50 y en la década de 1960 , proclive a crear, siguiendo la tendencia europea, un Tribunal Constitucional que pudiera ejercer un control preventivo de la constitucionalidad de los proyectos de ley o indicaciones formuladas a dichos proyectos.

En 1958 el profesor Francisco Cumplido en su obra Teoría de la Constitución, propuso incorporar al texto constitucional un tribunal llamado a interpretar la Constitución.

En 1963 se realizaron en la Biblioteca Nacional una serie de foros, dirigidos por el profesor Jorge Guzmán Dinator, en que se debatieron las reformas que convenía introducir a la Carta de 1925 y en que se recomendaba la creación de una Corte Constitucional.

En las Terceras Jornadas Chilenas de Derecho Público celebradas en la Universidad de Concepción, se recomendó la modificación de la Constitución creando un Tribunal formado en su mayoría por letrados, que tendría a su cargo determinadas facultades entre las que cabe destacar las siguientes: a) el control preventivo de la constitucionalidad de los proyectos de ley o indicaciones formuladas a dichos proyectos, a petición de Presidente de la República o de cualquiera de las Cámaras y b) el control, con efectos absolutos de la constitucionalidad de todas las leyes, tanto respecto de su contenido (inconstitucionalidad de fondo), cuanto en el procedimiento de su formación (inconstitucionalidad de forma).

Esta idea de consagrar un control preventivo de los proyectos de ley, propiciado como lo hemos visto por el ambiente jurídico y académico, se incorporó al proyecto de Reforma de la Constitución, formulado por el 
Presidente Frei, tuvo sus raíces, principalmente, en el vacío que se producía con la interpretación que la Corte Suprema hacía de la atribución que le otorgaba el artículo 86 inc. 2 de la Constitución de 1925, en el sentido que no aceptaba las inconstitucionalidades de forma.

De esta manera el control preventivo de los proyectos de ley fue una facultad que se entregó al nuevo órgano constitucional que se creaba, es decir al Tribunal Constitucional, como fruto de la experiencia política y jurídica chilena.

\section{EN CUANTO A LOS REQUISITOS PARA EJERCER EL RECURSO PREVIO CONVIENE ANALIZAR EL ORIGEN DE LA NORMA A PARTIR DE LA REFORMA DE 1970 QUE MODIFICÓ LA CONSTITUCIÓN DE 1925 Y EN EL ARTÍCULO 78 B) LETRA A) ESTABLECIÓ LO SIGUIENTE:}

a) "Resolver las cuestiones sobre constitucionalidad que se susciten durante la tramitación de los proyectos de ley y de los tratados sometidos a la aprobación del Congreso"

Esta norma es semejante a la de la actual Constitución, por lo que de su análisis resulta con claridad que para que el Tribunal ejerza esta atribución se requiere que concurran los mismos requisitos que exige la ley fundamental de 1980 .

Sobre el particular y refiriéndose, expresamente, al requisito de que exista una cuestión de constitucionalidad, los comentaristas se han pronunciado en general en el sentido de que para que opere esta exigencia es menester que exista una controversia pues el Tribunal no es órgano de consulta. titucional de 1970 sostiene:

Así, Alejandro Silva Bascuñán en el texto de la Reforma Cons-

"Conviene hacer notar también que las cuestiones de constitucionalidad que pueden entregarse a la decisión del Tribunal deben ser las que se susciten "durante la tramitación de los proyectos de ley", debiendo a nuestro juicio, entenderse que la tramitación comienza desde que se da cuenta en la respectiva Cámara de la iniciativa formal expresada a través del mensaje o moción correspondiente.

La afirmación precedente guarda armonía con las exactas palabras empleadas por el constituyente, escogidas para respetar fielmente la verdadera naturaleza de la función confiada al Tribunal Constitucional, que 
no es simple autoridad de consulta de cuestiones abstractas, sino que un órgano jurisdiccional llamado a resolver dificultades concretas que en la realidad hayan sufrido.

Por lo dicho, no sería procedente a nuestro parecer, que antes de toda formulación de un proyecto se requiera dictamen del Tribunal sobre el procedimiento a que debería someterse o sobre la conformidad o disconformidad de lo que se proyecte ordenar con la sustancia normativa de la Carta Orgánica".

\section{EL PROBLEMA SOBRE EL CONCEPTO DE CUESTIÓN DE CONSTITUCIONALIDAD SE DEBATIÓ EN EL TRIBUNAL CONSTITUCIONAL QUE ESTABLECIÓ LA CONSTITUCIÓN DE 1925 REFORMADA EN 1970}

Este Tribunal presidido por don Enrique Silva Cimma y en fallo redactado por éste, de 19 de enero de 1972, frente al planteamiento que para que el Tribunal pudiera conocer de una cuestión de constitucionalidad era menester que previamente ella se hubiera producido en alguna de las instancias del proceso formador de la ley, en el considerando $3^{\circ}$ expresó:

"Que tampoco puede aceptarse, como parecería deducirse de las objeciones contenidas en los escritos de observaciones ya citadas que para que este Tribunal conozca de una cuestión de constitucionalidad es menester que, previamente, ella se haya producido en alguna de las instancias anteriores del proceso formatorio de la ley en el Congreso, tanto porque no lo exige así en forma alguna el precepto ya mencionado de la letra a) del artículo 78 b), que se limita a disponer que el proyecto sólo esté en tramitación -y el de la especie, como se ha visto aún lo está- cuanto porque aquella alegación, de establecerse como requisito de cumplimiento riguroso equivaldría prácticamente a transformar este Tribunal en una especie de órgano de apelación, en vía jurisdiccional, lo que no se desprende de manera alguna ni del texto constitucional que lo creó ni de la historia fidedigna de su establecimiento".

En el fallo referido se rechazó la inadmisibilidad formulada, pues se estimó que no era la única forma de acción que permitía la Carta Fundamental, por lo que abocado el Tribunal a conocer por la vía del requerimiento directo, jurídica y constitucionalmente posible sólo le quedaba entrar a conocer del asunto y desechar la inadmisibilidad planteada.

En el mismo sentido previno el ministro Jacobo Schaulson diciendo: "Exigir que se 'promueva', esto es, inicie o 'suscite' la 'cuestión' o 
sea 'pregunta qué se hace o propone para averiguar de una cosa controvertiéndola' previamente ante el Congreso Nacional, fuera de que, como se ha dicho precedentemente, no lo exige la Constitución, podría hacer ilusorio el derecho para los titulares del recurso de inconstitucionalidad. En efecto, es fácil imaginar numerosas situaciones constitucionales o reglamentarias propias del funcionamiento del Congreso Nacional en que no existe forma ni manera para proceder antes por la vía que se echa de menos".

El ministro don Rafael Retamal fue voto disidente y estimó que la cuestión de constitucionalidad debe provocarse durante la tramitación de la ley. Se fundamentó en la historia del establecimiento de la norma y agregó: "La tesis del cuestionamiento previo en el Congreso la sostienen los constitucionalistas Francisco Cumplido, Guillermo Piedrabuena y Alejandro Silva en sus conocidos trabajos que figuran en el libro llamado "Reforma Constitucional, 1970 y la Reforma Constitucional". El primero de ellos funda su tesis en la historia del establecimiento de la ley.

\section{LA CUESTIÓN DE CONSTITUCIONALIDAD EN LA CONSTITUCIÓN DE 1980 ESTÁ PLANTEADA EN LOS MISMOS TÉRMINOS QUE EN LA CONSTITUCIÓN DE 1925 REFORMADA EN 1970}

La disposición pertinente -art. 82 № 2 transcrito en el cuerpo de este trabajoreproduce en términos, prácticamente iguales, la disposición de 1970 y viene a constituir la consagración del recurso previo en nuestra Carta Fundamental.

Para analizar los distintos fallos y las conclusiones que podemos extraer de ellos es menester, previamente, tener presente el tenor literal de la expresión "cuestión" y "suscitada".

De acuerdo con el Diccionario de la Real Academia por "cuestión" debe entenderse: "pregunta que se hace o propone para averiguar la verdad de una cosa controvertida".

En relación con el momento en que debe formularse la cuestión hay que considerar que debe ser "suscitada durante la tramitación" y por "suscitada" el mismo Diccionario señala que es "levantar, promover".

En conformidad a lo anterior y conforme al tenor literal de la Constitución es evidente que para que exista una "cuestión" debe existir una cosa controvertida y que ésta debe formularse o promoverse durante la tramitación del proyecto, es decir desde su presentación y antes de su promulgación.

La ley orgánica constitucional del Tribunal regulando esta 
materia en su art. 39 señala los requisitos que deben reunir los requerimientos en los casos de conflictos de constitucionalidad, que señala el artículo 82 № 2 de la Constitución.

Dice esta disposición:

"El requerimiento deberá contener una exposición clara de los hechos y fundamentos de derecho que le sirven de apoyo. Se señalará en forma precisa la cuestión de constitucionalidad y, en su caso, el vicio o vicios de inconstitucionalidad que se aducen, con indicación de las normas que se estiman transgredidas.

Al requerimiento deberán acompañarse en su caso, copias íntegras de las actas de sesiones de sala o comisión en las que se hubiere tratado el problema y de los instrumentos, escritos y demás antecedentes invocados.

En todo caso se acompañará el proyecto de ley de reforma constitucional o tratado con indicación precisa de la parte impugnada".

De estas exigencias debemos destacar:

a) Que debe señalarse en forma precisa la cuestión de constitucionalidad;

b) Que en su caso deben señalarse el vicio o vicios de inconstitucionalidad que se aducen;

c) Acompañar copia íntegra de las actas de las sesiones de Sala o Comisión, en que se hubiere planteado el problema.

De la simple lectura de estos requisitos aparece como indudable que en las actas de las sesiones de Sala o de Comisión debe constar una cosa o materia controvertida.

Si no fuera así, para qué se exigiría que se remitieran las actas y que se señalara el vicio o vicios e inconstitucionalidad que se alegan y las normas que se estiman transgredidas.

En cuanto a la expresión "en su caso" no creemos que deba entenderse, como han sostendio algunos autores, que significa "cuando proceda, cuando sea conveniente".

A nuestro juicio la frase del art. 39, antes transcrita, debe entenderse en relación con el art. 38 del mismo cuerpo legal, que distingue entre tres clases de requerimientos: los presentados por el Presidente de la República, por alguna de las Cámaras o por la cuarta parte de los miembros en ejercicio de una de las Cámaras.

La lectura del art. 39 nos hace llegar a la conclusión que siempre hay que indicar la cuestión de constitucionalidad, o sea, la materia 
controvertida y en todo caso o tratándose de cualquier requerimiento los vicios de constitucionalidad y las normas transgredidas.

VII. SOBRE LA MATERIA DE ESTE TRABAJO EXISTE JURISPRUDENCIA DEL TRIBUNAL CONSTITUCIONAL EN RELACIÓN CON LOS PROBLEMAS QUE SE HAN PLANTEADO: A) SE FORMULÓ AL TRIBUNAL LA INTERROGANTE SOBRE SI ESTE ÓRGANO JURISDICCIONAL PUEDE EMITIR DICTÁMENES O ABSOLVER CONSULTAS

En el rol № 23 se presentó un requerimiento para que el Tribunal resolviere diversas cuestiones de constitucionalidad que habían surgido durante la tramitación del proyecto de ley "que sanciona el tráfico ilícito de drogas y estupefacientes y deroga la Ley 17.934".

En el requerimiento se le formularon al Tribunal dos consultas en torno a las leyes penales en blanco.

Sentenciando la materia expresó en el considerando $4^{\circ}$ : que para que el Tribunal pueda ejercer la atribución que se le confiere deben concurrir copulativamente ciertas condiciones esenciales, como ser:

a) Que se suscite una cuestión de constitucionalidad, es decir, una discrepancia sobre la preceptiva constitucional entre los órganos colegisladores. Tal discrepancia puede surgir entre el Poder Ejecutivo y el Poder Legislativo o en el seno mismo del segundo.

b) Que la desigual interpretación de las normas constitucionales, en el caso en estudio, se produzca en relación a un proyecto de ley o a una o más de sus disposiciones.

c) Que la discrepancia que se suscite sobre la preceptiva constitucional en relación a las normas de un proyecto de ley sea precisa y concreta.

En el considerando $6^{\circ}$ el Tribunal resume lo anterior diciendo:

$6^{\circ}$ "Que de lo expuesto en los considerandos $3^{\circ}$ a $5^{\circ}$ fluye, con nitidez, que el Tribunal Constitucional, en el ejercicio de la facultad que le confiere el art. 82 № 2 de la Constitución, es un órgano jurisdiccional a quien la Carta Fundamental le ha confiado la misión de resolver cuestiones de constitucionalidad concretas que se susciten entre los órganos colegisladores, durante la tramitación de los proyectos de ley o de reforma constitucional de 
los tratados sometidos a la aprobación del Congreso, hoy de la Junta de Gobierno.

El Tribunal Constitucional, pues, no es un órgano de consulta sobre el sentido y alcance de la preceptiva constitucional que pueda incidir en futuros proyectos de ley, ni tampoco está autorizado para emitir dictámenes durante la tramitación de dichos proyectos, sobre materias jurídico-constitucionales abstractas o generales".

De la jurisprudencia citada resulta con claridad que la misión del Tribunal es resolver cuestiones concretas de constitucionalidad que se hayan presentado durante la tramitación de la ley, reforma constitucional o tratado.

Se fundamentan los sentenciadores en la opinión del profesor Alejandro Silva Bascuñán antes citada en este trabajo (considerando $4^{2}$ ).

Siguiendo esta doctrina el Rol 147 resolvió un requerimiento de constitucionalidad en relación a una asignación judicial y se remitió a lo ya dicho en el Rol 23, en el sentido de que para que exista una cuestión de constitucionalidad tiene que haberse producido, al menos, una discrepancia sobre la preceptiva constitucional y el texto legal impugnado en los órganos colegisladores.

El considerando $3^{\circ}$ dice:

3․ "Que de los antecedentes acompañados por los requirentes, especialmente de los Diarios de Sesiones de la H. Cámara de Diputados en que consta la discusión del proyecto, no se constata la existencia de una cuestión de constitucionalidad, más aún si se tiene en consideración que los requirentes no hicieron presente en la discusión de la iniciativa las objeciones constitucionales correspondientes".

Este considerando reitera lo expresado en el Rol 23 pero es de gran interés lo que se señala en la parte final de él, en el sentido que los requirentes no hicieron presentes en la discusión de la iniciativa las objeciones constitucionales.

En la tramitación del proyecto de ley gran parte de los requirentes se abstuvo de votar al tratarse la materia debatida y posteriormente firmaron el requerimiento.

El Tribunal si bien no desarrolla una doctrina al respecto deja entrever la idea que los requirentes estarían obligados, en la discusión de la iniciativa, a hacer presente las objeciones constitucionales correspondientes.

Este fallo sostiene la necesidad de la preparación del requerimiento.

El requerimiento no sería una alternativa de la que se pueda echar mano en cualquier momento, sin previo aviso o preparación. Se trataría 
de una instancia que sólo procede cuando el conflicto se ha exteriorizado $y$ no ha encontrado otro cauce de solución.

En razón de esta doctrina por resolución de 30 de mayo de 1995 se declaró inadmisible un requerimiento de inconstitucionalidad de los artículos quinto y quinto bis de la Ley de Rentas Municipales.

El Honorable diputado don Valentín Ferrada recurrió de reposición al Tribunal Constitucional sosteniendo que la cuestión de constitucionalidad estaba planteada por el solo hecho de presentar el requerimiento y que cualquier otra interpretación significa limitar y disminuir el derecho de los parlamentarios a acudir a la justicia constitucional en procura de pronunciamientos de fondo.

En esta forma el H. Diputado revivió la tesis de los ministros del Tribunal Constitucional de 1970, señores Enrique Silva Cimma y Jacobo Schaulson, tesis que el Tribunal actual ha rechazado, fundado en el tenor literal de la disposición, en el texto de la ley orgánica constitucional, en el origen de la norma y en la doctrina emanada de los comentaristas de la reforma constitucional de 1970 .

\section{EL PROBLEMA PLANTEADO EN ESTE TRABAJO SE REFIERE, ESPECÍFICAMENTE, A CUÁNDO HA DE ENTENDERSE CONFIGURADA UNA CUESTIÓN DE CONSTITUCIONALIDAD}

Hasta el momento el Tribunal lo ha resuelto (Rol № 23 y Rol № 147) definiéndose por la idea de la preparación previa del requerimiento, sin embargo existen ciertos problemas que sólo se han insinuado pero falta una doctrina elaborada al respecto.

Podríamos destacar sobre el particular ciertas situaciones, como por ejemplo la siguiente: se presentan al Tribunal requerimientos con el número de firmas que exige la Constitución, pero si se examina el trámite de formación de la ley, resulta que los requirentes han votado a favor de las disposiciones requeridas (ejemplo el requerimiento a la ley de trasplantes), o se han abstenido de votar como sucedió en el caso de la asignación judicial y que el Tribunal lo hizo presente en el Rol № 147.

El Tribunal no ha objetado hasta la fecha estos requerimientos y los ha admitido a tramitación, estimando que los parlamentarios pueden cambiar de opinión y adherir al cuestionamiento de constitucionalidad, pues no existe ninguna disposición que les prohiba actuar en esta forma.

Si bien se ha aceptado en forma generalizada que los requeri- 
mientos deben prepararse, planteándose una objeción concreta y precisa de constitucionalidad durante la tramitación de la ley, de la reforma constitucional o del tratado, quedan, sin embargo, otros problemas por resolver como es el caso que enunciábamos sobre los parlamentarios que votan favorablemente una norma o se abstienen y después requieren por inconstitucionalidad de la misma norma.

En este caso bien podría entenderse que el parlamentario ha retirado su voto, es decir, que se ha retractado, facultad que evidentemente no tienen los parlamentarios y que en ningún caso podría aceptarse pues sería reconocerles una atribución que no les han otorgado las normas contitucionales y legales; si asi se aceptara, atentaría contra los artículos 6 y 7 de la Constitución.

IX. EL TRABAJO QUE PRESENTAMOS A ESTAS JORNADAS ANALIZA PRINCIPALMENTE, EI SIGNIFICADO Y ORIGEN DE LA EXPRESIÓN "CUESTIÓN DE CONSTITUCIONALIDAD CUANDO EL TRIBUNAL HA SIDO REQUERIDO POR LOS PARLAMENTARIOS EN RAZÓN DE QUE NO HAYJURISPRUDENCIA EN EL CASO QUE REQUIERA EL CONGRESO"

Ahora bien, en el caso que requiera el Presidente de la República, sólo encontramos un caso y en la especie no se ha elaborado una doctrina del Tribunal, pues no le ha tocado pronunciarse en otras situaciones.

El requerimiento referido lo formuló el Ejecutivo en el caso de la planta de la Contraloría General de la República.

Al discutirse el informe de la Comisión la $\mathrm{H}$. senadora Laura Soto argumentó que el proyecto era propio de ley común y no de ley orgánica constitucional como se había aprobado por la Sala.

En este caso podría estimarse que la "cuestión de constitucionalidad" se había suscitado durante la tramitación de la ley.

Se ha sostenido, además, que el Presidente de la República puede hacer constar la cuestión por un oficio y que no es necesario que formule la alegación a través de uno de sus Ministros en un debate en Sala o Comisión (La cuestión de constitucionalidad - Carlos Carmona apuntes de clase).

Esta afirmación es dudosa y seguramente debe ser objeto de un mayor análisis cuando se presentan otros requerimientos del Ejecutivo. 


\section{-}

